\title{
Disaster Preparedness: Looking through the Lens of Hospitals in Japan
}

\author{
Farah Mulyasari*, Satomi Inoue, Sunil Prashar, Kenji Isayama, Mrittika Basu, Nitin Srivastava, and Rajib Shaw \\ Graduate School of Global Environmental Studies, Kyoto University, Kyoto 606-8501, Japan
}

\begin{abstract}
Critical facilities, such as hospitals, play a crucial role in the socioeconomic and psychological recovery of the population after a disaster. Hospitals are considered important due to their roles in saving lives in the affected population and must be able to withstand hazards and remain functioning during and after a disaster. This article assesses earthquake preparedness of hospitals in eight Japanese cities using a questionnaire survey. The questionnaire consists of six parameters and 21 indicators from the "four pillars of hospital preparedness" including structural, nonstructural, functional, and human resources. The results show that the majority of the respondent hospitals fulfill the functional preparedness, which is useful during the emergency period of a disaster, while the other three pillars-structural, nonstructural, and human resources-need to be strengthened. This study helps to assess the status of disaster preparedness as well as the gaps for these hospitals in the Tohoku and Nankai Trough regions, drawing lessons from the Great East Japan Earthquake and Tsunami of the Tohoku area. This status and the gaps are used as a departure point to indicate how to enhance preparedness and resilience to future disaster risks.
\end{abstract}

Keywords earthquake preparedness, four pillars of hospital preparedness, urban hospitals, Japan

\section{Introduction}

The World Disasters Report 2010 (IFRC 2010) warns that 2.6 billion people in urban areas in low- and middle-income nations are susceptible to high levels of risk generated by rapid urbanization, poor governance at the local level, unprecedented population growth, and poor health services. Cities by virtue of their locations and their setting in hazardprone landscapes contribute to their vulnerability, and have varying degrees of preparedness against disasters. UNISDR $(2009,9)$ defines disaster preparedness as "the knowledge and capacities developed by governments, professional response and recovery organizations, communities and individuals to effectively anticipate, respond to, and recover from, the impacts of likely, imminent or current hazard events or conditions." In spite of all the advancements in science and

\footnotetext{
* Corresponding author. E-mail: farah.mulyasari@gmail.com
}

technology, in most cities a major proportion of the inhabitants continue to be exposed to disaster threats. This can also be attributed to differential distribution of critical facilities, especially health facilities.

Health facilities play an important role in the socioeconomic and psychological recovery of the population from a disaster and are considered especially important because of their role in saving lives in the affected population. Their role is not only to provide medical care, but also to save patients at the time of disaster. Hospitals, as one kind of health facilities in cities must be able to withstand hazards and must remain functioning. For example, during and after Hurricane Ivan struck the island of Grand Cayman, Cayman Islands Hospital remained functional and provided shelter to more than 1,000 people, as it was built to Category 5 hurricane standards (UNISDR 2012). Damage to these facilities inhibits the relief and recovery operation, as can be seen in the 2011 Great East Japan Earthquake and Tsunami (GEJET) in Tohoku, Japan. The event caused total collapse of 11, and partial collapse of more than 200, hospitals in three prefectures (Iwate, Miyagi, and Fukushima) (World Bank 2012). The loss of hospital facilities highlights the enormous investments needed for disaster preparedness.

Despite the advancement of hospitals around the globe, they often are rendered useless due to structural failures at a time when these critical installations are required to save the lives of people affected by disasters. In the cases where the hospital buildings are structurally safe, capacity to provide assistance during the times of utmost need also is lacking. Reasons may be inadequate beds, lack of medical and support staff, equipment and facilities, or the increased number of patients needing medical attention. It is essential to protect and strengthen these hospitals. Hospitals are often associated with disaster response, yet they have a larger role to play in ensuring the safety of their particularly vulnerable clientele (PAHO/WHO 2005). Kai, Ukai, and Ohta (1994) conducted a study to investigate the adequacy of preparedness in the Osaka Prefecture in Japan and found that of the 265 hospitals surveyed, none could fulfill the criteria for disaster preparedness, which included sufficient electricity, gas, water, food, and medical supplies in the event of a disaster.

The number of disaster events reported around the globe has dipped in the last decade, yet the number of people 
directly and indirectly affected by catastrophes, and their related costs, is rising (Laframboise and Loko 2012). This demands safer hospitals for cities throughout the world. In considering such momentous challenges, this article determines the disaster preparedness of hospitals in cities, through a case study in Japan, and addresses the challenges of hospital preparedness. The following sections illustrate the issues related to disaster impact on hospitals and the global initiative of hospital preparedness, the background and concept of the medical service laws and system related to disaster in Japan, and the research approach used to assess the hospital preparedness in major cities. We discuss the results and findings from the survey and conclude with the challenges and way forward associated with hospital preparedness for disasters.

\section{Disaster Impact on Hospitals and the Hospital Preparedness Initiative}

Disaster impact on health sectors causes secondary disaster as a result of damages to the health facilities including hospitals. The 2004 Indian Ocean Tsunami severely affected 61 percent of hospitals in Aceh whose ability to function came to a halt in the crisis situation (United Nations 2009). Post-disaster impacts on hospitals differ due to several factors, such as type of disaster, vulnerability and capacity of the health system, and risk related conditions.

In developing health facilities, enormous investment is required, such as cost of reconstruction and recovery that impose a huge economic burden on a nation's economy after disasters. Disasters not only bring direct costs in terms of damage to hospital buildings, equipment, substitute facilities, and supplies but also bring indirect costs, which are often not completely accounted for and can be higher than the direct costs (United Nations 2009). For example, the indirect costs of the health sector due to disaster was estimated at around USD 13 billion in Latin America and the Caribbean between 1991-2002, higher than the costs of direct damage (United Nations 2009).

Hospital failure to withstand disaster brings immense social implications such as the effect on public morale as a result of death of the sick, elderly, and children in hospitals during disasters as well as failure of emergency services when they are most needed (United Nations 2009). Socioeconomic impacts on the health sector such as the cost of treating victims, the cost of sanitation, and epidemiological interventions and other effects on the provision of health care after a disaster can collectively raise social issues and ignite political dissatisfaction (PAHO/WHO 2003).

Hospital failure to withstand disaster also creates huge impacts on the health system due to deaths and injuries, delay in search and rescue operations, collapse of health services, chances of disease outbreaks, delay in the treatment of trauma injuries, collapse of emergency functions, and obstruction of ongoing public health and sanitation campaigns (United
Nations 2009). Delay or collapse of health services further creates long-term impact on the ability to achieve the Millennium Development Goals (PAHO/WHO 2005) and slows down the recovery process.

Delivering effective medical services in a disaster situation largely depends on the coordination system. When various agencies deal with medical emergency patients, lack of coordination coupled with conflict among agencies often leads to tremendous loss of time, waste of resources, duplication, and uncoordinated and inappropriate response, which is the root cause of inefficiency and further deteriorates the coordination level between partners (ADPC 2009). During emergencies, coordination of transport among all sectors and agencies is becoming an important priority and considered an important part of the integration strategy of medical service in several countries (ADPC 2009).

The complexity and occupancy of hospitals make them vulnerable to natural hazards. For example, their needs in terms of critical supplies - medicine, splints, bandages, and so on and basic demands - power, water, clinic gases, oxygen, and so on, are essential and at risk during disaster events (PAHO 2000). Spilled chemicals and damaged gas cylinders can lead to fires as a result of severe earthquakes (PAHO 2000). Several cases of fires were reported in hospitals after the 1995 Great Hanshin-Awaji earthquake in Kobe, Japan. Health-care facilities are occupied with around-the-clock medical and support staff, patients, and visitors, as well as patients who require an uninterrupted critical power supply for life-supporting equipment (PAHO 2000). Hospital operation also depends on external sectors. For example, roads and bridges affected by an earthquake can obstruct the Emergency Medical Services (EMS) in affected areas if hospitals can be accessed only through land transportation. Functionality of other sectors is essential for hospitals to be continuously operational during disasters.

In the recent past, several studies and global initiatives have addressed the health sector (including hospital) risk from disaster. Bissell et al. (2004) conducted a study on the effectiveness of health sector preparedness in disaster response. They examined fatality and survival data related to emergency preparedness levels by taking two earthquake cases from California, one from Armenia, and one from Kobe, Japan. The California earthquakes resulted in fewer fatalities (one death per 100 injuries) than the earthquakes in Kobe (31 deaths per 100 injuries) and Armenia (167 deaths per 100 injuries). To enhance health sector preparedness for disasters, several initiatives have been launched around the world, such as the Hyogo Framework for Action 2005-2015 (UNISDR 2005); the 2008-2009 World Disaster Reduction Campaign (United Nations 2009); and the Asian Disaster Preparedness Center's document: Safe Hospital: The Key to Deliver Effective Emergency Medical Services (ADPC 2009). Despite these efforts, the United Nations (2009) noted that in some parts of the world, health-care facilities, from large complex hospitals to rural clinics, are still built on disaster-prone sites. 
In Japan, the GEJET impacts on hospitals and social welfare services were massive. In Fukushima, Miyagi, and Iwate Prefectures around 80 percent of hospitals were either destroyed or severely damaged (World Bank 2012).

\section{Background of Hospital Preparedness in Japan}

Hospital preparedness for disasters in Japan has evolved because of past disaster experiences. Past disaster events and high casualties in the country have compelled the Japanese government to alter its laws and adopt the basic concepts of the medical service system for disaster. The continuous revision of the disaster management laws and the adoption of the basic concept are the fundamental factors why Japan has made efforts to make hospitals better prepared for disasters in the future. It is important to understand this rationale for hospital preparedness in Japan.

\subsection{Turning Points of Medical Service Law for Disasters}

Some major turning points of Japanese laws for medical service in disaster (Cabinet Office, Government of Japan 2011) are identified in Table 1. The Disaster Relief Act was established in 1947 following the Showa Nankai Earthquake in 1946. This act set a standard for post-disaster relief and rescue operations. The immense damage caused by Typhoon Ise-wan in 1959 gave rise to the preparation of the comprehensive disaster management system. In 1961, the Disaster Countermeasures Basic Act was enforced, which is the basis for disaster management in Japan. Thereafter, the disaster management system was improved and strengthened following the occurrence of other big disaster events.

The revision of the laws in the health sector was made to provide better medical service to the public. The 1947 Medical Service Law stipulates securing the provision of the medical care system and aims to contribute towards the maintenance of a healthy nation. The law also establishes the standards, requirements, and system of medical service of hospitals in Japan (Kawabuchi 2007). This law was revised in 1985, 1992, 1997, and 2001, based on changes in the social situation and aging progress in Japan. Based on the lessons learned from the 1995 Hanshin-Awaji Earthquake, the concept of the Disaster Base Hospital, ${ }^{\mathrm{i}}$ boundary of wide area disaster, and an emergency service information system were established, and the functions of public health centers pertaining to the disaster medical system were strengthened in the notification from the Ministry of Health, Labour and Welfare (MHLW) on health policy in 1996. In 2000, a further notification stipulated that a public health center was the base of the local health crisis control. In 2007, the fifth revision of the Medical Service Law made it compulsory for hospitals to make a hospital medical plan containing the hospital's medical service in disaster. Changes through the revisions of the Medical Service Law are listed in Table 2.

\subsection{The Concept of a Medical Service System for Disaster in Japan}

The goal of medical service during an emergency in Japan is to achieve the most effective way of treating large numbers of victims; therefore hospitals need to be well prepared for emergencies such as disasters. Various medical services that have been provided in disaster situation are as follows:

Command and Control, Safety, Communication, and Assessment (CCSCA) and Triage: The Command and Control, Safety, Communication, and Assessment (CCSCA) and Triage systems used in Japan in managing medical service during disasters are derived from the Major Incident Medical Management System (MIMMS) (Aitken and Leggat 2012). These systems are important due to their relevance in mass casualty and disaster management. The services are delivered by the emergency departments in hospitals, which are the "front door" of the hospital component of the health system. According to the MIMMS, "command" over the health service resources should be established immediately when an incident has occurred, while "control," as the overall direction of emergency management activities in an emergency situation, should be given equal importance, and "safety" should be treated as a priority in all activities. "Communication" is vital to the successful management of medical and other critical services during disasters. Radios as an alternative form of communication to conventional communication, such as telephone, have been installed in most hospitals in Japan. The "assessment" of hospital emergency preparedness should include multiagency support since external aid is crucial to reducing the inherent delays of service delivery (Woollard 2003). The most commonly used triage method in Japan is the Simple Triage and Rapid Treatment (START) method - a priority-based treatment system used for initial separation of patients based on their physical injuries and conditions.

Hub Hospital: A Hub Hospital is a hospital that is prepared for emergency medical treatment in an initial period. These hospitals were designated according to the lessons from the 1995 Hanshin-Awaji Earthquake and are required to: (1) be ready for response to an emergency $24 / 7$; (2) be capable to receive patients in serious condition by helicopter; and (3) have a Disaster Medical Assistant Team (DMAT). The number of Hub Hospitals in Japan totals 649 (EDMIS 2012).

Disaster Medical Assistant Team (DMAT): A DMAT is a trained medical team, consisting of two doctors, two nurses, and one support staff. It must be able to quickly respond to disasters and move to disaster-affected areas within 48 hours after a disaster or emergency. Based on experiences after the Hanshin-Awaji Earthquake, the purpose of DMATs' establishment is to save as many lives as possible. As of October 2012, 519 medical facilities and 1002 teams had been trained (MHLW 2012). During the Central Disaster Management Council meeting in 2005, the DMAT initiative was incorporated into the Basic Plan for Disaster Prevention (Kondo et al. 2010), based on the Disaster Countermeasures Basic Act of 
Table 1. Disaster management laws and major disasters in Japan

\begin{tabular}{|c|c|c|c|c|c|}
\hline Year & Disaster Management Law & Major Disaster & $\begin{array}{l}\text { Casualty and } \\
\text { Missing }\end{array}$ & Injured & Source \\
\hline 1946 & - & $\begin{array}{l}\text { (Showa) Nankai Earthquake } \\
\text { (M 8.0) }\end{array}$ & 1330 & - & $\begin{array}{l}\text { Cabinet Office, Government of Japan } \\
\text { (2011) }\end{array}$ \\
\hline 1947 & $\begin{array}{l}\text { Disaster Relief Act } \\
\text { Medical Service Law }\end{array}$ & & & & $\begin{array}{l}\text { Kawabuchi (2007); Cabinet Office, } \\
\text { Government of Japan (2011) }\end{array}$ \\
\hline 1948 & Medical Practitioners Law & & & & Kawabuchi (2007) \\
\hline 1959 & & Typhoon Ise-wan & 5098 & 38,921 & $\begin{array}{l}\text { Cabinet Office, Government of Japan } \\
\text { (2011) }\end{array}$ \\
\hline 1960 & $\begin{array}{l}\text { Soil Conservation and Flood Control Urgent } \\
\text { Measures Act }\end{array}$ & & & & $\begin{array}{l}\text { Cabinet Office, Government of Japan } \\
\text { (2011) }\end{array}$ \\
\hline 1961 & Disaster Countermeasures Basic Act & & & & $\begin{array}{l}\text { Cabinet Office, Government of Japan } \\
\text { (2011) }\end{array}$ \\
\hline 1962 & $\begin{array}{l}\text { Act Concerning Special Financial Support to } \\
\text { Deal with Designated Disasters of Extreme } \\
\text { Severity } \\
\text { Act of Special Countermeasures for Heavy } \\
\text { Snowfall Area }\end{array}$ & & & & $\begin{array}{l}\text { Cabinet Office, Government of Japan } \\
\text { (2011) }\end{array}$ \\
\hline 1964 & & $\begin{array}{l}\text { Niigata Earthquake } \\
(3534 \text { houses destroyed and } \\
11,000 \text { houses damaged })\end{array}$ & & & USGS (2012) \\
\hline 1966 & Act of Earthquake Insurance & & & & $\begin{array}{l}\text { Cabinet Office, Government of Japan } \\
\text { (2011) }\end{array}$ \\
\hline 1972 & $\begin{array}{l}\text { Act Concerning Special Financial Support for } \\
\text { Promoting Group Relocation for Disaster } \\
\text { Mitigation }\end{array}$ & & & & $\begin{array}{l}\text { Cabinet Office, Government of Japan } \\
\text { (2011) }\end{array}$ \\
\hline 1985 & The First Revision of Medical Service Law & & & & Kawabuchi (2007) \\
\hline 1992 & The Second Revision of Medical Service Law & & & & Kawabuchi (2007) \\
\hline 1995 & $\begin{array}{l}\text { Revision of Disaster Countermeasures Basic } \\
\text { Act }\end{array}$ & $\begin{array}{l}\text { The Hanshin-Awaji Earth- } \\
\text { quake (M 6.8) }\end{array}$ & 6437 & 43,792 & $\begin{array}{l}\text { Cabinet Office, Government of Japan } \\
\text { (2011) }\end{array}$ \\
\hline 1996 & $\begin{array}{l}\text { Notification from Ministry of Health, Labour } \\
\text { and Welfare About Disaster Medical System }\end{array}$ & & & & MHLW (1996) \\
\hline 1997 & The Third Revision of Medical Service Law & & & & Kawabuchi (2007) \\
\hline 1999 & $\begin{array}{l}\text { Act Concerning Support for Reconstructing } \\
\text { Livelihoods of Disaster Victims } \\
\text { Sediment Disaster Countermeasures for } \\
\text { Sediment Disaster-Prone Areas Act }\end{array}$ & Torrential Rains in Hiroshima & 32 & & $\begin{array}{l}\text { Cabinet Office, Government of Japan } \\
\text { (2011); Hiroshima Prefectural } \\
\text { Government (2011) }\end{array}$ \\
\hline 2000 & $\begin{array}{l}\text { Notification from Ministry of Health, Labour } \\
\text { and Welfare About Health Crisis and the } \\
\text { Function of the Public Health Center in } \\
\text { Disaster }\end{array}$ & & & & MHLW (2000) \\
\hline 2001 & The Fourth Revision of Medical Service Law & & & & Kawabuchi (2007) \\
\hline 2004 & & $\begin{array}{l}\text { The Niigata-ken Chuetsu } \\
\text { Earthquake (M 6.8) }\end{array}$ & 68 & 48,805 & $\begin{array}{l}\text { Cabinet Office, Government of Japan } \\
\text { (2011) }\end{array}$ \\
\hline 2007 & The Fifth Revision of Medical Service Law & $\begin{array}{l}\text { The Niigata-ken Chuetsu-oki } \\
\text { Earthquake (M 6.8) }\end{array}$ & 15 & 2345 & $\begin{array}{l}\text { Cabinet Office, Government of Japan } \\
\text { (2011); Kawabuchi (2007) }\end{array}$ \\
\hline 2011 & & $\begin{array}{l}\text { The Great East Japan } \\
\text { Earthquake and Tsunami } \\
\text { (M 9.0) }\end{array}$ & 18,559 & 6144 & $\begin{array}{l}\text { National Police Agency of Japan } \\
\text { (2013) }\end{array}$ \\
\hline
\end{tabular}


Table 2. Revisions of the Medical Service Law in Japan

\begin{tabular}{|c|c|c|}
\hline Revision & Year & Subject \\
\hline First & 1985 & $\begin{array}{l}\text { - Regional Medical Service Plan is developed. The plan determined how many beds are to be provided for each medical } \\
\text { service area. Prefectures were required to keep the set number } \\
\text { - Reduce the quantity of hospital beds to provide better quality of medical services }\end{array}$ \\
\hline Second & 1992 & $\begin{array}{l}\text { - Designate specific functions to hospitals (Hospital for Highly Advanced Medicine and Extended Care Beds) } \\
\text { - Provide more health-care information to the public (types of services provided, hospital facilities, and the care system by } \\
\text { nurses were allowed to be advertised) } \\
\text { - Clarify and express the direction health care in Japan should aim for (building trust between the provider and the recipient) } \\
\text { - Maintain the quality of outsourcing services (maintain the quality of services from outside by providing certification with a } \\
\text { certain level of quality) } \\
\text { - Approve certain related business to be run by health-care entities (allowing health-care units to run facilities such as athletic } \\
\text { clubs and spas) }\end{array}$ \\
\hline Third & 1997 & $\begin{array}{l}\text { - Extension of an Extended Care Bed system to clinics } \\
\text { - Establishment of Regional Care Hospital } \\
\text { - Preparation of rules on related business by health-care units }\end{array}$ \\
\hline Fourth & 2001 & $\begin{array}{l}\text { - Change in the bed classification } \\
\text { - More deregulation in advertisement } \\
\text { - Mandatory clinical training for doctors and dentists }\end{array}$ \\
\hline Fifth & 2007 & $\begin{array}{l}\text { - Financial reform: control in health-care costs } \\
\text { - Reform of delivery system: control on number of beds } \\
\text { - Reform on manpower: strengthening and competition } \\
\text { - Establishment of the Social Health Care Corporation } \\
\text { - Review of Medical Service Plan } \\
\text { Regional health-care network established (for each of the emergency medical services; evaluated once every five years) }\end{array}$ \\
\hline
\end{tabular}

Source: Kawabuchi (2007).

1961. DMATs in disaster-affected areas are deployed and perform their activities in coordination with the headquarters (Kondo et al. 2010) (Figure 1).
Emergency Medical Information System: This system was developed based on the experiences from the 1995 HanshinAwaji Earthquake. It is an information network that includes

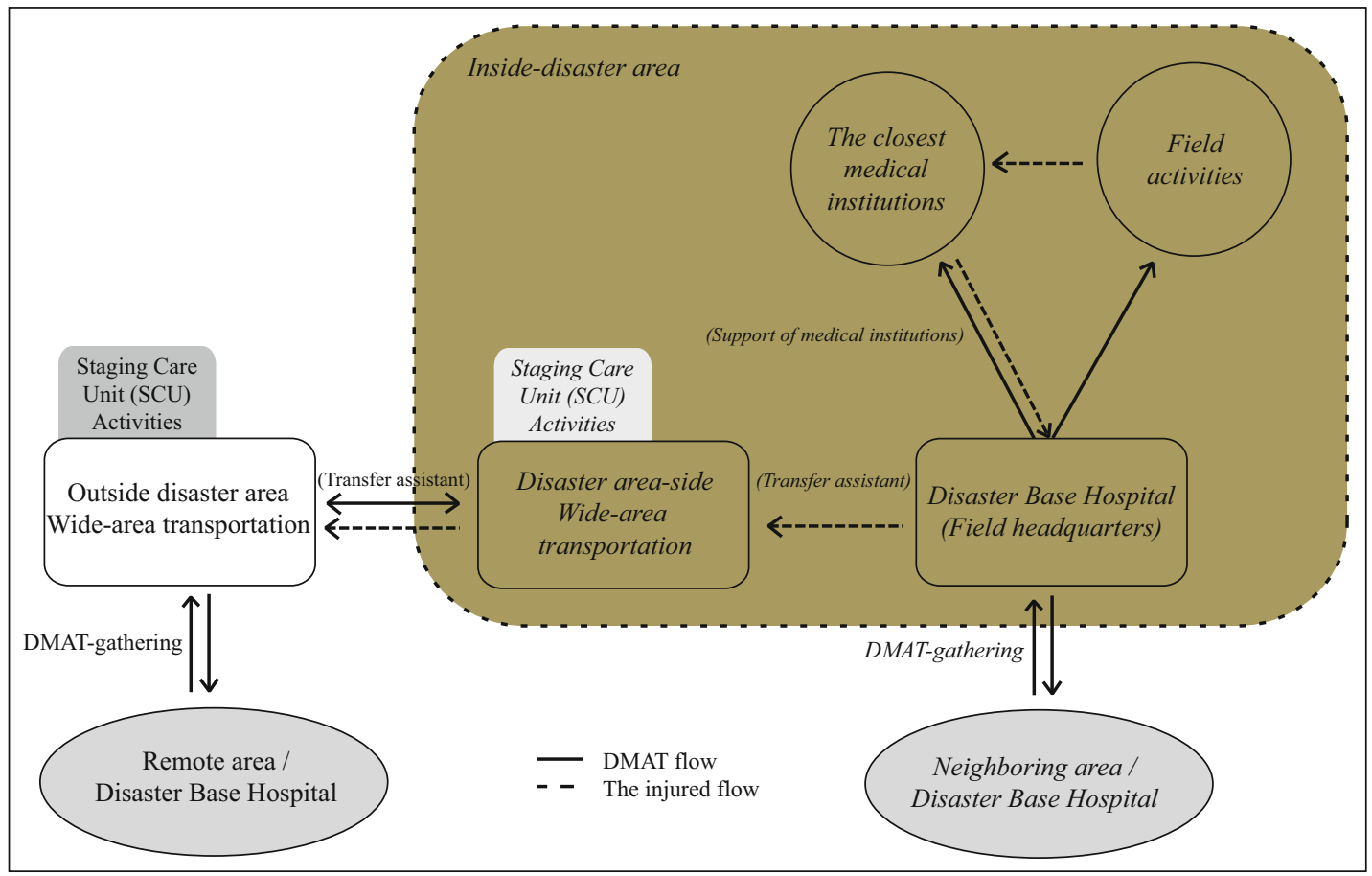

Figure 1. Disaster medical system and Disaster Medical Assistant Team (DMAT) activities in Japan Source: Adapted from Kondo et al. (2010). 
hospitals, number of total beds occupied, and medical support information, connects organizations, including MHLWrelated ministries, prefectures' relevant departments, and related organizations such as Disaster Base Hospitals, through the Internet, and is accessible by the public (Kondo 2007).

\section{Research Methods}

A safe hospital should not collapse in disasters and cause casualties of patients and staff, but should continue to function and provide services as a critical facility for the community when it is most needed. A hospital should be equipped with contingency plans and have an operational network in place. To ensure that hospitals in Japan meet these criteria and are prepared for disasters, this study examines the four pillars of hospital preparedness based on the Hospital Safety Index (HSI) approach (PAHO/WHO 2008) and the assessment of vulnerability elements at hospitals.

\subsection{Hospital Safety Index (HSI)}

According to PAHO/WHO (2012), a "safe hospital" is a facility whose services remain accessible and functioning at maximum capacity and within the same infrastructure immediately following a natural disaster. The Pan American Health Organization (PAHO) and WHO (PAHO/WHO 2008) developed a Hospital Safety Index (HSI), a tool to provide a snapshot of the feasibility that a hospital will continue to function in emergency situations, considering the structural, nonstructural, functional, and human resources issues, including the environment and health services network to which the hospital belongs. The HSI is an initial step towards prioritizing investments in hospital preparedness. By determining a hospital's safety index, decision makers will have an overall idea of the hospital's ability to respond to major emergencies and disasters, allowing a hospital's level of safety to be monitored over time. The HSI was developed by PAHO's Disaster Mitigation Advisory Group (PAHO DiMAG) and specialists in Latin America and the Caribbean and applied in countries such as Mexico, Bolivia, Ecuador, Peru, and in the Caribbean.

\subsection{Vulnerability Elements of Hospitals}

According to PAHO and WHO, vulnerability elements of hospitals to potential hazards such as earthquakes include the following (PAHO/WHO 1996, 2003; WHO 2007):

Buildings: Susceptibility of buildings comprises the design, resiliency of the materials, and physical vulnerability, which determine the ability of hospitals to withstand adverse natural events. Collapse or failure of a minor structural or architectural element results in both financial and human loss.

Patients: To serve the patients, it is compulsory for health facilities to work 24 hours a day at about 50 percent of their service capacity. Any disaster will increase the number of potential patients, amplifying their level of risk. The waiting lists for patients in need of regular care will become longer, since it will be impossible to handle both the routine care and the demand generated by emergency situations. The patients are also vulnerable in terms of the decline in the provision of services as a result of damaged and/or partially evacuated or nonoperational facilities.

Hospital Beds: In the aftermath of a disaster, the availability of hospital beds will frequently decrease, as the demand will increase due to the emergency cases of the injured.

Medical and Support Staffs: The casualties among medical specialists can entail major loss for the country affected by a disaster and could add to the overall economic burden. In order not to suffer from the collateral loss in the response capacity, outsourcing has to be employed temporarily.

Equipment and Facilities: Damage to nonstructural elements (such as equipment, furniture, architectural features, and medical supplies) can occasionally be severe and surpass the cost of structural elements. Even when damages are less costly, they can still be critical enough to force hospitals to halt their operation.

Basic Lifelines and Services: The ability of hospitals to function relies on lifelines and other basic services such as electric power, water and sanitation, communications, and waste management and disposal. Not all health facilities may be equipped with backup emergency services; when a natural disaster affects some of these services, the performance of an entire hospital is affected.

\subsection{The Four Pillars of Hospital Preparedness}

Combining the safety approach of the HSI and the vulnerability elements of hospitals, the parameters and indicators of the preparedness of hospitals in the study area were developed (Table 3). These were then transformed into a questionnaire, which was distributed to the target hospitals in the area, and completed by a person from the management department at each hospital. General information such as the name of the hospital (not identified here) and number of beds, buildings, total floors, hospital staff, doctors, nurses, and hospital technicians (X-ray department, blood laboratories, and so on) were asked as well. This is important information on hospital capacity in terms of physical and human resources. Nurses, especially nurse leaders, are in a unique position due to their ability to supervise multiple tasks simultaneously, encourage participation of personnel, and execute change in times of disaster (Fahlgren and Drenkard 2002). Hospitals not only have physical capacity limits but also are limited with respect to human resources (experts) in their capacity to manage a sudden surge of people who might need the service in a time of disaster (Rebmann et al. 2009).

Hospitals were also asked about their experiences in past disaster events and the lessons learned. The assessment was targeted at two regions in Japan, the Tohoku and Nankai Trough regions. 
Table 3. Hospital preparedness parameters and indicators in the study area in Japan

\begin{tabular}{|c|c|c|c|}
\hline Vulnerability Elements & Preparedness & Parameter & Indicator \\
\hline Buildings & $\begin{array}{l}\text { STRUCTURAL PREPAREDNESS } \\
\text { (The ability of the buildings' structure to } \\
\text { withstand hazard events: the location of the } \\
\text { building, materials, design) }\end{array}$ & Buildings & $\begin{array}{l}\text { - Earthquake- and fireproof building construction } \\
\text { - Natural hazard location check } \\
\text { - Space available for emergency evacuation }\end{array}$ \\
\hline Equipment and Facilities & $\begin{array}{l}\text { NONSTRUCTURAL PREPAREDNESS } \\
\text { (The ability of the buildings' nonstructural } \\
\text { element to withstand hazard events } \\
\text { (equipment, partition, walls, ceilings, } \\
\text { windowpanes, and so on) }\end{array}$ & Medicine Management & $\begin{array}{l}\text { - Medicines/chemicals/potential hazardous } \\
\text { substance management } \\
\text { - Material Safety Data Sheets (MSDS) standards }\end{array}$ \\
\hline \multirow[t]{3}{*}{$\begin{array}{l}\text { Patients } \\
\text { Hospital Beds } \\
\text { Basic Lifeline and Service } \\
\text { Equipment and Facilities }\end{array}$} & \multirow[t]{3}{*}{$\begin{array}{l}\text { FUNCTIONAL PREPAREDNESS } \\
\text { (The ability of the hospital to operate } \\
\text { properly: accessibility, hospital beds, } \\
\text { necessary supplies available on site, basic } \\
\text { lifeline service, safety measures) }\end{array}$} & $\begin{array}{l}\text { Stocks for Hospital } \\
\text { Facilities in Emergency }\end{array}$ & $\begin{array}{l}\text { - } \text { Medical equipment for emergency medical } \\
\text { - } \text { Mervice } \\
\text { - } \quad \text { Tents for emergency medical service } \\
\text { - } \text { In-house power generator } \\
\text { - } \quad \text { Drinking water } \\
\text { - Food } \\
\text { - Folded beds } \\
\text { - } \quad \text { Triage tags }\end{array}$ \\
\hline & & Communication & $\begin{array}{l}\text { - Emergency medical information system } \\
\text { - Other communication tools/devices for } \\
\text { emergency }\end{array}$ \\
\hline & & Transportation & $\begin{array}{l}\text { - } \text { Helipad space } \\
\text { - } \text { Accessibility (roads) } \\
\text { - Car for Disaster Medical Assistance Team } \\
\text { (DMAT) }\end{array}$ \\
\hline Medical and Support Staffs & $\begin{array}{l}\text { HUMAN RESOURCES } \\
\text { (The existence and the ability of medical } \\
\text { staff, such as doctors, nurses, laboratory } \\
\text { technicians to prepare for hazard events) }\end{array}$ & $\begin{array}{l}\text { Disaster Preparedness of } \\
\text { Medical and Support } \\
\text { Staffs }\end{array}$ & $\begin{array}{l}\text { - Availability/implementation of education/ } \\
\text { training for emergency medical service } \\
\text { - Implementation of disaster drill for hospital } \\
\text { staff/workers and patients } \\
\text { - Availability of DMAT framework }\end{array}$ \\
\hline
\end{tabular}

The hospitals in the Tohoku region were asked about their experiences in GEJET, such as to what extent the disasters affected those hospitals, what kind of lessons were learned, and what kind of messages those hospitals would like to convey to hospitals in other cities. The hospitals in the Nankai Trough region were asked about their past disaster experiences in terms of disasters' impacts and their specific disaster preparedness and hospital challenges regarding future disasters. Regardless whether the hospitals were directly affected by past disasters such as the 1995 Great Hanshin-Awaji Earthquake and the 2011 GEJET, hospitals were asked about what changes have been implemented in terms of their disaster preparedness due to the influence of those past disasters.

\subsection{Data Collection}

The data were collected through the questionnaire survey of the target hospitals (55) in eight prefectural capital cities in Japan. The selection criteria of the target hospitals were as follows: (1) in a capital city; (2) have more than five departments; and (3) prone to the Nankai Trough earthquake and/or have experienced the GEJET. Most of the questionnaires were distributed by mail and some by fax with a given timeframe (12-29 June 2012) for completion. Out of 55 hospitals, 14 hospitals responded to the survey: four hospitals (two Hub Hospitals and two General Hospitals) from one city in the Tohoku region and 10 hospitals (five Hub Hospitals and five General Hospitals) from seven cities in the Nankai region.

\section{Findings and Discussion}

The analysis of the questionnaires was done quantitatively using Excel as well as qualitatively, based on the questions that were posed to hospitals. The findings focus on the responses of the hospitals concerning the different preparedness indicators (Table 3 ) and past disaster experiences. The results are presented and summarized in Table 4.

\subsection{Structural Preparedness}

In terms of structural preparedness, the vulnerability element is related to the building construction in terms of earthquake and fire safety, hazard mapping, and space availability for 
Table 4. Summary of the hospital preparedness assessment in the Tohoku and Nankai regions of Japan

\begin{tabular}{|c|c|c|c|c|c|c|c|c|c|c|c|c|c|c|c|c|c|c|c|c|}
\hline \multirow[t]{3}{*}{ Hospital } & \multirow{2}{*}{\multicolumn{3}{|c|}{$\begin{array}{c}\begin{array}{c}\text { Structural } \\
\text { Preparedness }\end{array} \\
\text { Buildings }\end{array}$}} & \multirow{2}{*}{\begin{tabular}{|c|}
$\begin{array}{c}\text { Non Structural } \\
\text { Preparedness }\end{array}$ \\
Arrangement
\end{tabular}} & \multicolumn{13}{|c|}{ Functional Preparedness } & \multicolumn{3}{|c|}{ Human Resources } \\
\hline & & & & & \multicolumn{8}{|c|}{ Stocks for Hospital Facilities in Emergency } & \multicolumn{2}{|c|}{ Communication } & \multicolumn{3}{|c|}{ Transportation } & \multicolumn{3}{|c|}{$\begin{array}{c}\text { Disaster } \\
\text { Preparedness } \\
\text { of Medical and } \\
\text { Support Staff }\end{array}$} \\
\hline & 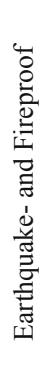 & 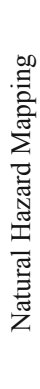 & 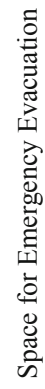 & 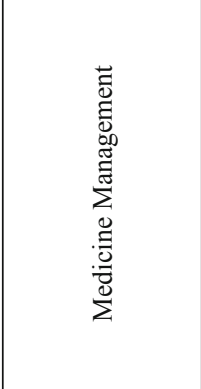 & 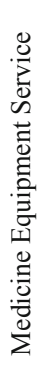 & 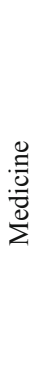 & $\stackrel{\overrightarrow{0}}{\stackrel{\overrightarrow{0}}{\oplus}}$ & 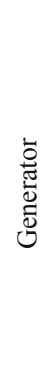 & 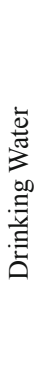 & $\begin{array}{l}\overrightarrow{8} \\
8 \\
1\end{array}$ & 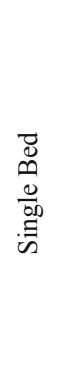 & 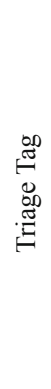 & 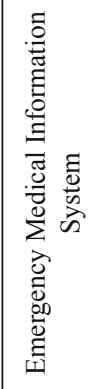 & 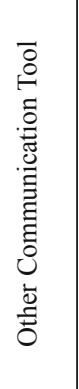 & 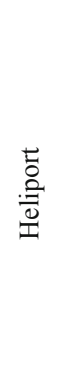 & 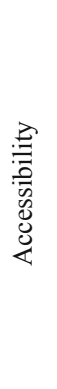 & 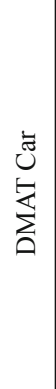 & 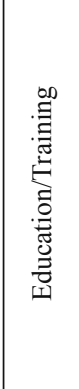 & 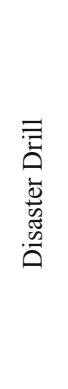 & 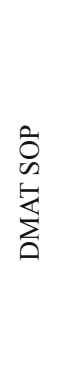 \\
\hline NT 1 & + & - & + & - & + & + & + & + & + & + & + & + & + & + & + & + & + & - & + & + \\
\hline NT 2 & + & - & + & + & + & + & + & + & + & + & + & + & + & + & - & + & - & + & + & - \\
\hline NT 3 & + & + & + & + & + & + & + & + & + & + & + & + & + & + & - & + & - & + & + & + \\
\hline NT 4 & + & + & + & - & + & + & - & + & + & + & + & + & + & - & - & + & - & + & + & - \\
\hline NT 5 & + & + & + & - & + & + & + & + & + & + & - & + & + & + & + & + & - & + & + & - \\
\hline NT 6 & + & - & + & nd & + & + & + & + & + & + & + & + & + & + & + & + & - & + & + & + \\
\hline NT 7 & + & + & + & + & + & + & + & + & + & + & + & + & + & + & + & + & + & + & + & + \\
\hline NT 8 & - & - & + & + & + & + & - & + & + & + & - & + & - & + & - & + & + & nd & + & + \\
\hline NT 9 & + & - & + & - & + & + & + & + & + & + & + & + & + & - & + & + & + & - & + & + \\
\hline NT 10 & + & - & + & - & + & + & + & + & - & + & + & + & + & + & + & + & + & + & + & nd \\
\hline $\mathrm{T} \mathbf{1}$ & + & + & + & - & + & + & + & + & + & + & + & + & + & + & + & + & + & + & + & + \\
\hline $\mathrm{T} 2$ & + & + & + & + & - & - & - & + & + & + & + & + & + & - & - & + & + & + & + & + \\
\hline T3 & + & + & + & + & + & + & + & + & + & + & + & + & + & + & + & + & + & + & + & + \\
\hline $\mathrm{T} 4$ & + & - & + & + & - & - & + & + & + & + & - & + & - & - & - & + & + & - & + & - \\
\hline
\end{tabular}

Note:

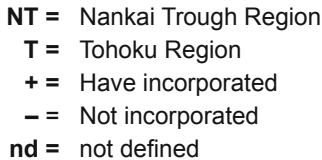

emergency evacuation. Out of 14 respondent hospitals, only one hospital has not (yet) constructed their buildings earthquake and fire safe (Table 4), while the other 13 hospitals have incorporated the seismic building code in the construction. Hospitals that are earthquake resistant and able to withstand disaster events can deliver better medical service to their beneficiaries. Hazard mapping also has not always been taken into consideration. Half of the hospitals responded that they have not checked whether the hospitals are located in hazard-prone areas (Table 4). This implies that those hospitals have not implemented earthquake risk mapping or any other hazard risk mapping, which means they are assuming that the locations of the hospitals are not in the danger zone despite seismic resistant buildings having been constructed. The possibility of being prone to other hazards than earthquake is also unknown and therefore hazard mapping has to be strongly promoted and required prior to construction. Another issue of structural preparedness is the availability of space for evacuation in the hospital area during emergency. The majority of the hospitals ( 80 percent) responded that they have some space available for evacuation during emergencies. The rest of the hospitals responded that they do not have enough space available, cannot accommodate large numbers of evacuees during emergencies, and are thus less prepared.

\subsection{Nonstructural Preparedness}

In terms of nonstructural preparedness the vulnerability element is medicine management, such as medicines/chemicals/ potential hazardous substance management and Material 
Safety Data Sheets (MSDS) standards. Most of the respondent hospitals are following their own manual for the management of medicines and hazardous supplies and have not applied the MSDS standards. A few are following the MSDS standards and one hospital does not have any manual at all (Table 4). Insufficient internal medicine management preparedness of these hospitals may lead to other disasters, such as spilling of hazardous materials that would trigger fires and building collapse (PAHO 2000). This could disrupt the medical service deliverance and cause additional casualties.

\subsection{Functional Preparedness}

In terms of functional preparedness the vulnerability elements are stocks for hospital facilities in emergency, communication, and transportation. They are indicated by several factors including: (1) stocks for hospital facilities (medical equipment for emergency, medicine for emergency, tents for emergency medical service, in-house power generator, drinking water, food, folded beds, triage tags); (2) communication (emergency medical information system and other communication tools/devices for emergency); and (3) transportation (heliport space, road accessibility, and car for DMAT) (Table 4).

Stocks for Hospital Facilities: Table 4 shows that all the respondent hospitals have in-house power generators for electricity supply during emergency, food stocks, and sufficient triage tags. In terms of water supply for drinking and other purposes, some hospitals responded that they might not have enough provision in case a disaster occurs. As per medical equipment for emergency service, medicine stocks, tents for emergency, and folded beds, only a few of the hospitals responded that they did not have enough provision. The availability of medical equipments, tents, and folded beds is measured by how many sets (responses range from 1-120 sets) the hospital could provide, and the provision of medicine is measured by for how many persons and days (responses range from 500-900 persons in 3 days) the hospital could deliver its service. Electricity, food, and water supply are measured by for how many days (responses range from 3-14 days) the hospital could provide such supplies during an emergency. Triage tags are measured by how many tags per person (one hospital in Nankai region has prepared up to 3000 tags) the hospital can provide during an emergency period. Almost all 14 hospitals have enough various stocks or supplies to be used during disasters. Having enough stocks and supplies may likely support the hospital preparedness. Critical supplies are essential on a daily basis and during disaster times (PAHO 2000).

Communication: All 14 hospitals have installed the emergency medical information system and utilized alternative communication tools, such as satellite phones, radios, and trans-receivers (Table 4). This means that all the respondent hospitals have prepared to use communication devices during an emergency period, in case the normal communication is disrupted. Reliance on one communication method is susceptible to disasters, as this may fail, overload, or become insufficient (Aitken and Leggat 2012). Having alternative communication devices as backup is one of the essential indicators for hospital preparedness.

Transportation: Eight out of 14 hospitals have a helipad on site (Table 4). It shows the extent to which the hospitals are prepared and able to deliver extra medical service to their beneficiaries. This medical service is mostly provided by the designated Hub Hospitals that have more available human resources, capacity of beds, and large construction size. Many of the respondent hospitals have DMAT cars (Table 4). The transportation parameter shows whether a hospital has adequate transportation vehicles in case of a disaster. All the respondent hospitals can easily be accessed through broad road networks (Table 4). These qualities show how well hospitals are prepared in terms of transportation that enables them to be accessed by land and by air, if a disaster occurs.

\subsection{Human Resources}

In terms of human resources, the vulnerability element includes disaster preparedness of medical and support staffs, indicated by the availability or implementation of education/ training for emergency service, implementation of disaster drills for hospital staff/workers and patients, and the availability of a Standard Operation Procedure (SOP) for the DMAT. Most of the respondent hospitals have education or training programs for emergency medical service and conducted disaster drills for hospital staff at least once a year (Table 4). One hospital in the Tohoku region is conducting disaster drills not only involving the staff but patients as well. This shows that most of the respondent hospitals have prepared for disasters in terms of enhancing the capacity of their human resources. Ten hospitals responded positively to having SOP for the DMAT, which means they have a clear Standard Operation Procedure. Three hospitals answered that they do not have a clear SOP (whether they have a SOP at all for the DMAT is unknown), and one hospital in the Nankai region responded that it has one Disaster Medical Assistance Team, but whether it has a clear SOP for the DMAT is unknown (Table 4).

The respondent hospitals have largely met the most fundamental requirements of preparedness such as stocks for hospital supplies, particularly food, drinking water, and generator for power supply, followed by earthquake- and fireproof building, accessibility, disaster drill, and triage tag requirements. Meeting these requirements indicates a high level of preparedness. Some of the hospitals are weak in the implementation of preparing space for emergency evacuation - they have provided some space, but perceived that as insufficient. The utilization of the MSDS standard is also unsatisfactory - instead of following the MSDS, many utilize their own manuals for the management of medicine and hazardous materials. 
Past Disaster Experiences: The respondent hospitals in the Tohoku region shared their experiences from the 2011 GEJET, which mostly affected the hospitals' buildings and lifeline installations. The most affected installations were pipes for water supply and electricity supply networks. One of the hospitals survived two days without water, two days of electricity from its own generator, and one and half months without gas supply. In terms of lessons learned, one hospital identified an important good practice from the logistics' point of view-they were collaborating with hospitals from the same group in transporting the medicines and foods. For messages to hospitals in other cities, hospitals in Tohoku emphasized the importance of conducting routine disaster drills or exercises and training for various emergency situations so that the flexibility and routine to respond to different situations in disasters will be maintained. Other crucial issues include networking with other hospitals and logistics, since these will be the backbone of medical service deliverance in disaster situations.

Hospitals in the Nankai region pointed out the importance of adapting hospital disaster preparedness plans based on experiences from the past disaster events, particularly the recent 2011 GEJET. The changes they have implemented cover the areas of lifeline, stocks of food and water, medicine, and communication. Most of the respondent hospitals have increased the frequency of disaster drills and the amount of necessary stocks such as triage tags. Following this, one of the respondent hospitals in Nankai has been approved as the Hub Hospital. One hospital is revising its earthquake disaster manual that covers all four pillars of preparedness (Table 4). These changes indicate that the recent disaster event promoted the improvement of the preparedness of hospitals in other regions. Hospitals in Japan that did not experience these disasters are now more aware of the importance of their own disaster preparedness.

\section{Challenges and the Way Forward}

Hospitals are the first line of disaster preparedness that must be safe with one hundred percent operation capabilities through each day of the year. The assessment of disaster preparedness of hospitals is essential, as there has been a growing number of disasters across the world and hospital preparedness is highly significant especially after the 2011 GEJET. Although the response rate of the survey in this study is low, this study presents an initial assessment of hospital preparedness for disasters from some of the most important earthquake-prone regions of Japan and identified the preparedness as well as the gaps of the health facilities of these areas. The results of this research can be used as a departure point to build up further resilience of the hospitals to future risks. The study highlights the lack of space available for emergency evacuation, low coverage of hazard mapping, and insufficiency in internal medicine management in many of the hospitals that may disrupt the normal delivery of basic services. The majority of hospitals have, in store, enough stocks and supplies of medicines, foods, beds, triage tags, and tents, sufficient communication devices, and transportation services that will be useful during emergency.

This study is limited in scope to seismic hazards. Followup studies are required on other geological and hydrometeorological disasters. Apart from the presence of normal patients, various hospital staff and visitors have not been considered in any of the four pillars of hospital preparedness. This study also did not incorporate elements of mental health, psychosocial well-being, and recovery after disasters.

Collaboration between the private and the public sectors in order to render efficiently and effectively available medical services for communities should be promoted as much as possible. The policy should not be to admit all patients to the casualty departments of hospitals but rather to take in patients who require emergency care at the hospitals, and refer the non-emergency patients to other health-care services. Local physicians, who can also become disaster victims, play a major role in providing care for local populations, though fatigue among medical personnel is a recurrent issue. Shortage of medical personnel (physicians and nurses) continues to be a challenge in Japan, even in the absence of a disaster (NBR 2011). The lack of robust systems to support information and resource sharing among hospitals and neighboring health-care coalitions also has negatively affected the disaster preparedness of hospitals. This study emphasizes the need of guidance on crisis care standards for a nation's health-care system that outlines health-care roles, responsibilities, and actions before, during, and after a disaster.

Preparing for disasters is a daunting task, not so much because of the depth of the issue but because of its breadth. It is important for hospitals to perform risk assessments and readiness assessments. Once these are done, it will be a far more manageable task to remedy the identified gaps. It is also important to integrate volunteers into the disaster response system of hospitals. Meeting with local people, spreading awareness about the immediate steps to be carried out during and post-disaster, and training by/for health personnel before disaster contribute in making the society more resilient to hazards. It is incumbent on hospitals to take the initiative on this issue since it falls between the cracks of the health-care and public safety systems. Local medical personnel who typically practice outside the hospitals need to practice disaster response in collaboration with their hospital counterparts. As Smith, Gorski, and Vennelakanti $(2010,218)$ stated, "issues pertaining to hospital accreditation, training curricula on disaster preparedness, qualified personnel and adequate resources, including health expenditures for disasters and assessment of response capabilities, are universal needs." Governments are in a position to provide leadership but it takes collaboration among public and private health-care sectors, and individual hospitals and hospital groups to protect and care for populations affected by disasters. Improving preparedness of hospitals is a global need. 


\section{Acknowledgments}

The authors gratefully acknowledge the cooperation of hospitals in the Tohoku and Nankai regions. The authors are also thankful to the Japanese Government (Mobunkagakusho, MEXT) for the scholarship and the support received from the Global Center of Excellence Program entitled "Global Center for Education and Research on Human Security Engineering for Asian Megacities" (GCOE-HSE) and Environmental Management Leader (EML) Program of Graduate Schools of Global Environmental Studies, Kyoto University in conducting this study.

\section{Note}

i Disaster Base Hospital is equal to Hub Hospital for disaster response. Disaster Base Hospital is a word-for-word translation from Japanese. Hub Hospital for disaster response is a translation in the general sense to emphasize its important role relating to transportation.

\section{References}

ADPC (Asian Disaster Preparedness Center). 2009. Safe Hospital: The Key to Deliver Effective Emergency Medical Services. Public Health in Emergency Team, Asian Disaster Preparedness Center. http://www. adpc.net/v2007/ikm/ONLINE\%20DOCUMENTS/downloads/ ADUMP/SafeHospitalKeytodelivereffectiveEMS.pdf.

Aitken, P., and P. Leggat. 2012. Considerations in Mass Casualty and Disaster Management. In: Emergency Medicine: An International Perspective, edited by B. Michael, 145-182. http://cdn.intechopen. com/pdfs/31947/InTechConsiderations_in_mass_casualty_and_ disaster_management.pdf.

Bissell, R. A., L. Pinet, N. Nelson, and M. Levy. 2004. Evidence of the Effectiveness of Health Sector Preparedness in Disaster Response: The Example of Four Earthquakes. Family and Community Health 27 (3): 193-203.

Cabinet Office, Government of Japan. 2011. Disaster Management in Japan. http://www.bousai.go.jp/panf/saigaipanf.pdf (in Japanese).

EDMIS (Emergency Disaster Medical Information System). 2012. Emergency Disaster Medical Information System in Japan. http:/ www.wds.emis.go.jp/WDTPIRYOSR/ACTBWDTPIRYOSR01.do (in Japanese).

Fahlgren, T. L., and K. N. Drenkard. 2002. Healthcare System Disaster Preparedness, Part 2: Nursing Executive Role in Leadership. JONA 32 (10): 531-537.

Hiroshima Prefectural Government. 2011. 1999. 6.29 Heavy Rain Disaster (Hiroshima-shi, Kure-shi). http://www.pref.hiroshima.lg.jp.e.bq. hp.transer.com/soshiki/100/1171538334545.html.

IFRC (International Federation of Red Cross and Red Crescent Societies). 2010. World Disasters Report 2010. Focus on Urban Risk. Geneva: International Federation of Red Cross and Red Crescent Societies.

Kai, T., T. Ukai, and M. Ohta. 1994. Hospital Disaster Preparedness in Osaka, Japan. Prehospital Disaster Medicine 9 (1): 29-34.

Kawabuchi, K. 2007. The Fifth Revision and the Beyond: Health Care Reform in Japan. Japan Hospitals: The Journal of Japan Hospital Association. Special Feature. 56th Annual Congress of Japan Association/Symposium 5 (July 8, Okayama). Coordinating Regional Medical Systems - The Troubles of Hospitals and Solutions for Them. No. 25, 11-18.
Kondo, H. 2007. Recent Trends of Disaster Medical System. Prehospital Emergency Care 20 (4): 7-12 (in Japanese).

Kondo, H., Y. Koido, K. Morino, M. Homma, Y. Otomo, Y. Yamamoto, and H. Henmi. 2010. Establishing Disaster Medical Assistance Teams in Japan. Prehospital Disaster Medicine 24 (6): 556-564.

Laframboise, N., and B. Loko. 2012. Natural Disasters: Mitigating Impact, Managing Risks. International Monetary Fund Working Paper 2012, WP/12/245. External Relations Department, Western Hemisphere Department.

MHLW (Ministry of Health, Labour and Welfare). 1996. Ministerial Notification About Disaster Medical System. Ministry of Health, Labour and Welfare, Japan. http://www.mhlw.go.jp/ (in Japanese).

MHLW (Ministry of Health, Labour and Welfare). 2000. Ministerial Notification about Health Crisis and the Function of the Public Health Center in Disaster. Ministry of Health, Labour and Welfare, Japan. http://www1.mhlw.go.jp/topics/kaisei/tp0518-1_b_11.html (in Japanese).

MHLW (Ministry of Health, Labour and Welfare). 2012. MHLW White Paper. Ministry of Health, Labour and Welfare, Japan. http://www. mhlw.go.jp/wp/hakusyo/kousei/12-1/dl/gaiyou.pdf (in Japanese).

National Police Agency of Japan. 2013. Damage Situation and Police Countermeasures associated with 2011 Tohoku District - off the Pacific Ocean Earthquake. http://www.npa.go.jp/archive/keibi/biki/ higaijokyo_e.pdf.

NBR (The National Bureau of Asian Research: Centre for Health and Ageing). 2011. Looking to the Future: Healthcare Reform and Disaster Preparedness Planning in Japan, An Interview with Dr. Makoto Aoki by Rebecca Kennedy and Karuna Luthra. Seattle, Washington. http://www.nbr.org/downloads/pdfs/CHA/NBR_Interview_Makoto Aoki.pdf.

PAHO (Pan American Health Organization). 2000. Principles of Disaster Mitigation in Health Facilities. Disaster Mitigation Series. http://www.paho.org/english/dd/PED/mit3-intro.pdf.

PAHO/WHO (Pan American Health Organization/World Health Organization). 1996. Proceedings, International Conference on Disaster Mitigation in Health Facilities. Mexico City, January 1996. Document LC/MEX/L.2911. ECLAC, Mexico City.

PAHO/WHO (Pan American Health Organization/World Health Organization). 2003. Protecting New Health Facilities from Natural Disasters: Guidelines for the Promotion of Disaster Mitigation. http://www.preventionweb.net/files/629_10343.pdf.

PAHO/WHO (Pan American Health Organization/World Health Organization). 2005. Safe Hospitals: A Collective Responsibility, a Global Measure of Disaster Reduction. http://www1.paho.org/english/dd/ ped/SafeHospitalsBooklet.pdf.

PAHO/WHO (Pan American Health Organization/World Health Organization). 2008. Hospital Safety Index: Evaluation Forms for Safe Hospitals. Hospitals Safe from Disasters. Washington DC: Pan American Health Organization.

PAHO/WHO (Pan American Health Organization/World Health Organization). 2012. What Is a Safe Hospital? http://safehospitals. info/index.php?option $=$ com_content $\&$ task $=$ blogcategory $\& \mathrm{id}=55 \&$ Itemid $=192$.

Rebmann, T., R. Wilson, S. LaPointe, B. Russell, and D. Moroz. 2009. Hospital Infectious Disease Emergency Preparedness: A 2007 Survey of Infection Control Professionals. American Journal of Infection Control 37 (1): 1-8.

Smith, S. M., J. Gorski, and H. C. Vennelakanti. 2010. Disaster Preparedness and Response: A Challenge for Hospitals in Earthquake-Prone Countries. International Journal of Emergency Management 7 (3-4): 209-220.

UNISDR (United Nations International Strategy for Disaster Risk Reduction). 2005. Hyogo Framework for Action 2005-2015: Building the Resilience of Nations and Communities to Disasters. http:// www.unisdr.org/files/1037_hyogoframeworkforactionenglish.pdf. 
UNISDR (United Nations International Strategy for Disaster Risk Reduction). 2009. UNISDR Terminology on Disaster Risk Reduction. Geneva: UNISDR.

UNISDR (United Nations International Strategy for Disaster Risk Reduction). 2012. How to Make Cities More Resilient - A Handbook for Local Government Leaders. A contribution to Global Campaign 2010-2015, Making Cities Resilient - My City is Getting Ready! Geneva: UNISDR.

United Nations. 2009. Hospitals Safe from Disasters. 2008-2009 World Disaster Reduction Campaign. Technical Guidance, United Nations. http://www.unisdr.org/2009/campaign/pdf/wdrc-2008-2009information-kit.pdf.
USGS (United States Geological Survey). 2012. Historic Earthquake Niigata, Japan 1964 June 16 04:01 UTC Magnitude 7.5. http:// earthquake.usgs.gov/earthquakes/world/events/1964_06_16.php.

World Bank. 2012. Protecting Significant and Sensitive Facilities. Knowledge Note 1-5. Cluster 1: Structural Measures. http://wbi. worldbank.org/wbi/Data/wbi/wbicms/files/drupal-acquia/wbi/ drm kn1-5.pdf.

WHO (World Health Organization). 2007. Disaster Risk Reduction and Preparedness of Health Facilities: A Literature Review. WHO Kobe Centre.

Woollard, M. 2003. Miracles Take a Little Longer: The Challenges of the Uncompensated Major Incident. Trauma 5 (1): 71-76.

Open Access This article is distributed under the terms of the Creative Commons Attribution License which permits any use, distribution, and reproduction in any medium, provided the original author(s) and source are credited. 